\title{
A FUNÇÃO GEOESTRATÉGICA DAS ÁGUAS SUBTERRÂNEAS PARA OS PAÍSES PLATINOS
}

\author{
Vera Lucia Fortes Zeni \\ Universidade do Estado de Santa Catarina- UDESC, Chapecó, SC, Brasil \\ verazeni@yahoo.com.br \\ Larissa de Lima Trindade \\ Universidade Federal da Fronteira Sul - UFFS, Chapecó, SC, Brasil \\ larissa.trindade@uffs.edu.br \\ Luiz Fernando Scheibe \\ Universidade Federal de Santa Catarina, Florianópolis, SC, Brasil \\ scheibe2@gmail.com
}

\begin{abstract}
RESUMO
A Bacia Platina é das mais extensas do mundo, composta por três grandes sistemas hídricos: rios Paraná, Paraguai e Uruguai, que formam o Rio da Prata (estuário), e abriga um dos mais estratégicos aquíferos, o Sistema Aquífero Integrado Guarani/Serra Geral (SAIG/SG). Por meio de pesquisa bibliográfica e documental o artigo tem o objetivo de demonstrar a função geoestratégica das águas subterrâneas para os países da Bacia do Prata: Brasil, Paraguai, Uruguai, Argentina e Bolívia. O trabalho evidencia que essas águas transfronteiriças configuram elemento de solidariedade entre esses países, exercendo função essencial, expressada nos aspectos econômicos, sociais e ambientais. Contudo, algumas práticas cotidianas, como a mercantilização da água, geram aspectos contrários à globalização da solidariedade, como o exacerbamento do individualismo e a difusão de territorialidades de controle. O modelo liberal vigente de crescimento econômico é ilimitado, especializado em algumas espécies produtivas, e não respeita os processos naturais e seus tempos. Neste aspecto, os impactos em escala local podem ser atribuídos a uma demanda de escala internacional na busca por espaços para produzir, especialmente nas regiões com fartura de água, como é o caso da Bacia Platina, ocasionando gradativamente a destruição e a transferência desse patrimônio.
\end{abstract}

Palavras-chave: Águas Subterrâneas. Bacia do Prata. Aquíferos Estratégicos.

\section{THE GEOSTRATEGIC FUNCTION OF UNDERGROUND WATERS FOR THE COUNTRIES OF THE LA PLATA BASIN}

\begin{abstract}
The La Plata Basin is one of the most extensive in the world, composed of three large water systems: Paraná, Paraguay and Uruguay Rivers, which form the Rio da Prata (estuary), and comprises also one of the most strategic aquifers, the Guarani/Serra Geral Integrated Aquifer System (SAIG/SG). Through bibliographic and documentary research, the article aims to demonstrate the geostrategic function of groundwater for the countries of the La Plata Basin: Brazil, Paraguay, Uruguay, Argentina and Bolivia. The work shows that these transboundary waters constitute an element of solidarity between these countries, exercising a primary function expressed in different economic, social and environmental aspects. Nevertheless, it is observed that daily practices generate the commercialization of water with its aspects contrary to the globalization of solidarity, like the exacerbation of individualism and the spread of control territorialities. The current liberal model of economic growth is unlimited, specialized in some productive species, and does not respect natural processes and their periods. In this respect, impacts on a local scale can be attributed to a demand on an international scale in the search for spaces to produce, especially in regions with plenty of water, such as the La Plata Basin, with the gradual destruction and transfer of this heritage.
\end{abstract}

Keywords: Underground Waters. La Plata Basin. Strategic Aquifers. 
sistemas aquíferos do ponto de vista hidrogeológico, institucional-legal, socioeconômico e socioambiental (SOUZA; SILVA; BARBOSA, 2014, p. 266).

A Organização dos Estados Americanos (OEA, 2009) estabeleceu que os países decidiram reconhecer o Tratado da Bacia do Prata $^{3}$ como a base legal para suas futuras ações no SAG. Entretanto, entendem que o SAG, por sua importância estratégica e pela dinâmica de suas águas, requer atenção especial. Por isso, organizou-se um Conselho Regional de Cooperação, que está estruturado através de comitês técnicos coordenados pelos países membros:

Comitês Técnicos é a institucionalização, no novo âmbito, das comissões técnicas criadas pelo PSAG e apoiarão o desenvolvimento dos instrumentos de gestão na Etapa de Implementação do seu Programa Estratégico de Ação - PEA. O Comitê de Sistema de Informação fica a cargo da Argentina. O Comitê de Monitoramento e Modelação fica a cargo do Brasil. O Comitê de Capacitação e Difusão fica a cargo do Paraguai. O funcionamento do Escritório de Articulação fica a cargo do Uruguai (OEA, 2009, p. 43).

O Conselho Regional de Cooperação, determina que o objetivo central é apoiar os países para o desenvolvimento de um marco para a proteção e desenvolvimento sustentável do SAG. As pesquisas realizadas no âmbito do PSAG resultaram em muitos dados, registrados no documento intitulado Aquífero Guarani: Programa Estratégico de Ação (OEA, 2009). Os estudos realizados ajustam sua área a $1.087 .879 \mathrm{~km}^{2}$, que corresponde a $92 \%$ da estimativa original, de $1.196 .500 \mathrm{~km}^{2}$. Foi confirmado, também, que o SAG está presente no subsolo dos quatro países, contudo, mostra algumas diferenças em relação às áreas estimadas originalmente (OEA,2009).

Quanto às faixas de afloramento, a pesquisa elaborada pela OEA usou como base a definição dos limites pela presença de arenitos dos limites estruturais na região do Alto Las Breñas-Otumpa, nas Províncias de Chaco e Santiago del Estero, no norte da Argentina, e limites estratigráficos ao norte e ao sul dessas estruturas, onde a espessura dos arenitos do SAG começa a diminuir até desaparecer. Já a definição do limite sudoeste baseia-se no reconhecimento das unidades que constituem o aquífero no subsolo, principalmente a partir da avaliação de dados provenientes de poços de petróleo perfurados oportunamente na região da Bacia Chacoparanaense.

$\mathrm{Na}$ região sul do território brasileiro há uma faixa importante de afloramento lesteoeste, "localizada no Estado do Rio Grande do Sul; e uma faixa norte-sul localizada no nordeste do Uruguai. (...) A parte sul do aquífero também se caracteriza pela escassez de afloramentos, principalmente em território argentino, e pela quantidade insuficiente de poços que permitam localizar seu limite (OEA, 2009, p. 115).

As áreas de descarga estão localizadas nas regiões de Entre Ríos (Argentina), Rio Uruguai (Santa Catarina e Rio Grande do Sul) e Pontal do Paranapanema (São Paulo, Mato Grosso do Sul e Paraná). O fluxo das águas subterrâneas do SAG apresenta uma tendência de direcionamento nortesul, acompanhando o eixo da Bacia (Geológica) Sedimentar do Paraná, a partir da confluência entre os estados do Paraná e Mato Grosso do Sul (Brasil) e do território paraguaio (OEA, 2009), sendo que áreas de afloramento possuem dinâmica própria.

A pesquisa efetuada pela UNESCO em 2010, para conhecer o 'estado da arte' dos Aquíferos das Américas, define como importante necessidade de ser apresentada de forma clara a localização das zonas de recarga e descarga dos aquíferos. Isso identifica suas vulnerabilidades e necessárias intervenções, "Os mapas da zona de recarga recentemente preparados podem ser sobrepostos a mapas de propriedades do aquífero, densidade populacional e uso do solo para identificar áreas de vulnerabilidade que requerem intervenções de gestão imediata" (UNESCO/ISARM AMERICAS, 2010, p. 22).

Ao longo da área do Rio Paraná, foi reconhecida uma zona na qual o SAG apresenta artesianismo condição natural de surgências das águas nos poços tubulares - sendo coletadas informações completas sobre 1.348 poços no mesmo. Esse fenômeno ocorre em uma faixa de $300 \mathrm{~km}$ de comprimento localizada nos estados de São Paulo, Mato Grosso do Sul e Paraná (norte do estado), mostrando-se mais estreita ao sul e alcançando, provavelmente, a província de Corrientes, na Argentina.

\footnotetext{
3 Tratado da Bacia do Prata, assinado entre o Brasil, Argentina, Bolívia, Paraguai e o Uruguai em Brasília, a 23 de abril de 1969, com objetivo de exploração integrada, racional e harmônica do sistema hidrográfico platino.
}

$\begin{array}{lllll}\text { Caminhos de Geografia } & \text { Uberlândia-MG } & \text { v. 23, n. } 85 & \text { fev./2022 } & \text { p. 191-203 Página } 193\end{array}$


Existe uma segunda região de artesianismo na fronteira entre os territórios uruguaio e argentino, ao longo do Rio Uruguai, faixa que possui uma largura aproximada de $50 \mathrm{~km}$. Com relação à vazão específica, a maior parte dos poços apresenta valores menores que $6 \mathrm{~m}^{3} / \mathrm{h} / \mathrm{m}$, havendo uma maior concentração de poços com vazão específica abaixo de $2 \mathrm{~m} 3 / \mathrm{h} / \mathrm{m}$. A temperatura das águas, na maior parte de sua área confinada, varia de $35{ }^{\circ} \mathrm{C}$ a $55{ }^{\circ} \mathrm{C}$. As máximas registradas são de aproximadamente $65^{\circ} \mathrm{C}$, mas há áreas limitadas nas quais a temperatura pode chegar a $80^{\circ} \mathrm{C}(\mathrm{OEA}$, 2009 , p. 122, 123, 128). O Brasil, além de ser privilegiado com grandes reservas de águas superficiais e subterrâneas, possui áreas de recarga geoestratégicas. O SAG abrange oito estados que desempenham importante papel no cenário econômico nacional, com as seguintes áreas:" Mato Grosso do Sul, com uma área de $213.200 \mathrm{~km}^{2}$, Rio Grande do Sul, com $157.600 \mathrm{~km}^{2}$, São Paulo, com $155.800 \mathrm{~km}^{2}$, Paraná, com $131.300 \mathrm{~km}^{2}$, Goiás, com $55.000 \mathrm{~km}^{2}$, Minas Gerais, com $52.300 \mathrm{~km}^{2}$, Santa Catarina, com $49.200 \mathrm{~km}^{2}$ e Mato Grosso, com $26.400 \mathrm{~km}^{2}$ " (RIBEIRO, 2011, s/p).

As águas do SAG constituem um recurso estratégico para abastecimento público e desenvolvimento regional dos países platinos. Dados obtidos na pesquisa da OEA (2009), apresentados na Tabela 1 confirmam a dimensão demográfica na área de abrangência desse sistema.

Tabela 1 - Dados demográficos da população sobre o SAG, baseados no ano de 2008.

\begin{tabular}{|c|c|c|c|}
\hline País & $\begin{array}{c}\text { População sobre o } \\
\text { SAG }\end{array}$ & $\begin{array}{l}\text { Porcentagem da } \\
\text { população do país }\end{array}$ & $\begin{array}{c}\text { Porcentagem da } \\
\text { população total do } \\
\text { SAG }\end{array}$ \\
\hline Argentina & 7.947 .667 & 20.59 & 8,64 \\
\hline Brasil & 80.141 .415 & 42,99 & 87,04 \\
\hline Paraguai & 3.263.318 & 55,91 & 3,54 \\
\hline Uruguai & 724.768 & 21,92 & 0,78 \\
\hline Total & 92.077 .168 & 46,67 & 100 \\
\hline
\end{tabular}

Ortega e Portillo (2015, p. 41) asseguram que as reservas de água do "Aquífero Guaraní estão estimadas em aproximadamente $40.000 \mathrm{~km}^{3}$, com uma recarga anual de $160 \mathrm{~km}^{3}$, podendo satisfazer uma demanda de água de 360 milhões de habitantes, (estimada em 300 litros diários por pessoa) ao longo de 100 anos". Contudo, uma eventual ameaça ao abastecimento de água em qualquer dos quatro países provocará um desequilíbrio na segurança hídrica dos países, fato demonstrado na Tabela 1 pelas parcelas expressivas da população brasileira, 42,99\%, e paraguaia $55,91 \%$, localizadas sobre o aquífero.

Soldera (2016, p. 10) afirma que se o "[...] descontrole da exploração das águas subterrâneas acontece, pode ocorrer que o aquífero exceda a sua capacidade de recarga natural, e isso pode ocasionar a queda dos níveis de sua água e em decorrência da queda a reserva hídrica [...]", o que acabará afetando os rios e nascentes que recebem água do aquífero mesmo em períodos em que não chove.

\section{Outros Aquíferos na Bacia do Prata}

Devido à imensa extensão territorial, a Bacia do Prata, além do SAG, possui outros aquíferos importantes, em regiões estratégicas para uso da sociedade, e pelo fator geológico o acesso às suas águas torna-se facilitado. Conforme registra a Figura 1, todos esses principais aquíferos platinos são compartilhados por dois ou mais países. 


\section{AQUÍFEROS TRANSFRONTEIRIÇOS DA BACIA DO PRATA}

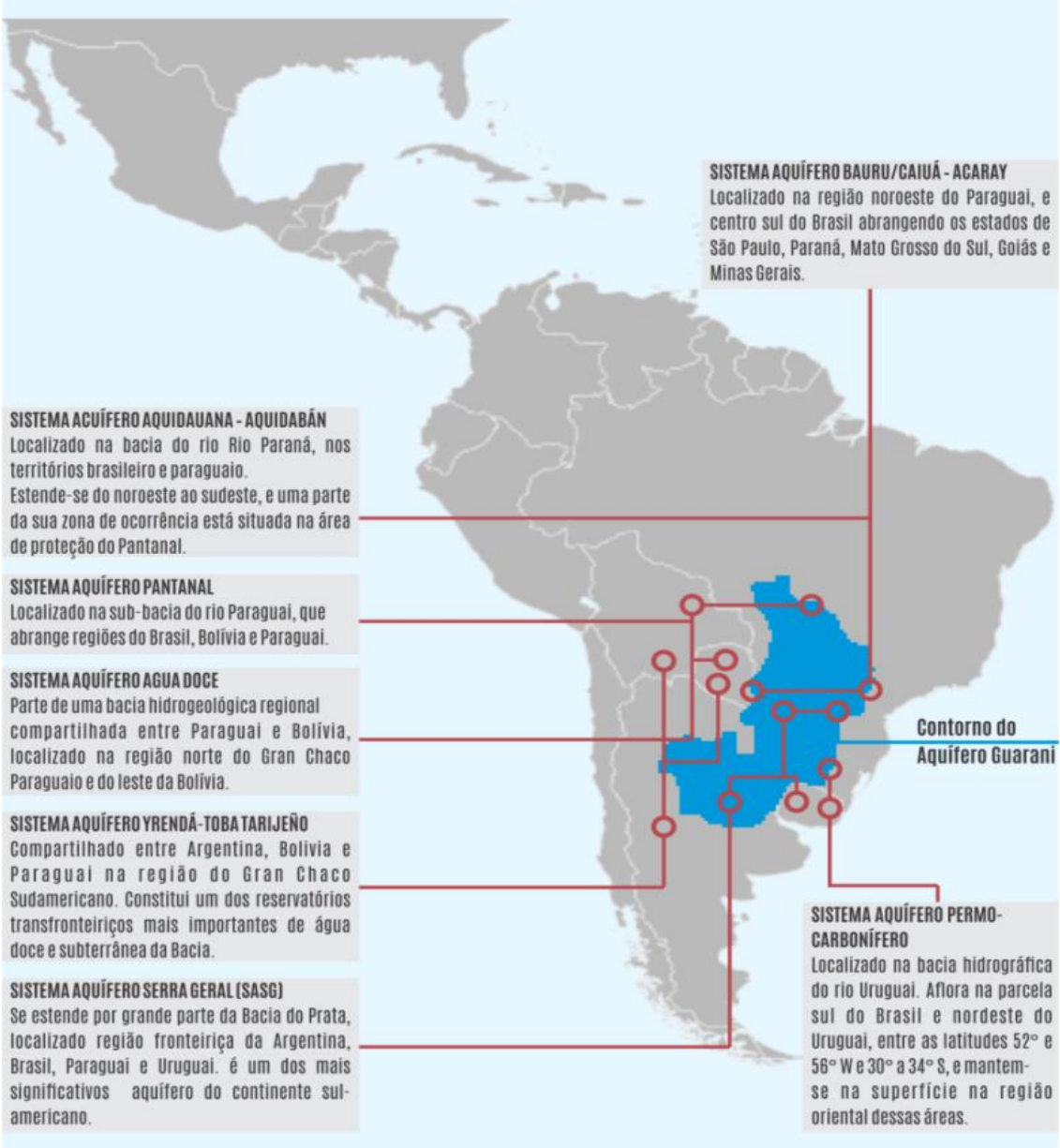

Fonte: Elaborado pelos autores com base em dados do CIC (2016).

Esses outros sistemas aquíferos que se destacam na Bacia do Prata serão discutidos nas próximas seções.

\section{Sistema Aquífero Yrendá-Toba-Tarijeño (SAYTT)}

O SAYTT (Figura 2) está localizado em território com carência de água, pouco volume pluviométrico e clima semiárido do Gran Chaco americano, é compartilhado pela Bolívia (3.064 km²), Argentina $\left(250.000 \mathrm{~km}^{2}\right)$ e Paraguai $\left(31.170 \mathrm{~km}^{2}\right)$. Trata-se de um aquífero estratégico e necessário à população local e às comunidades indígenas. Segundo pesquisas do CIC (2016) e UNESCO/ISARM AMERICAS (2010), cerca de 400.000 habitantes residem na área e utilizam suas águas para usos domésticos, irrigação e pecuária em geral; No Paraguai, em época de secas, é a única fonte de água em sua área de ocorrência. 
Figura 2 - Sistema Aquífero Yrendá-Toba-Tarijeño (SAYTT)

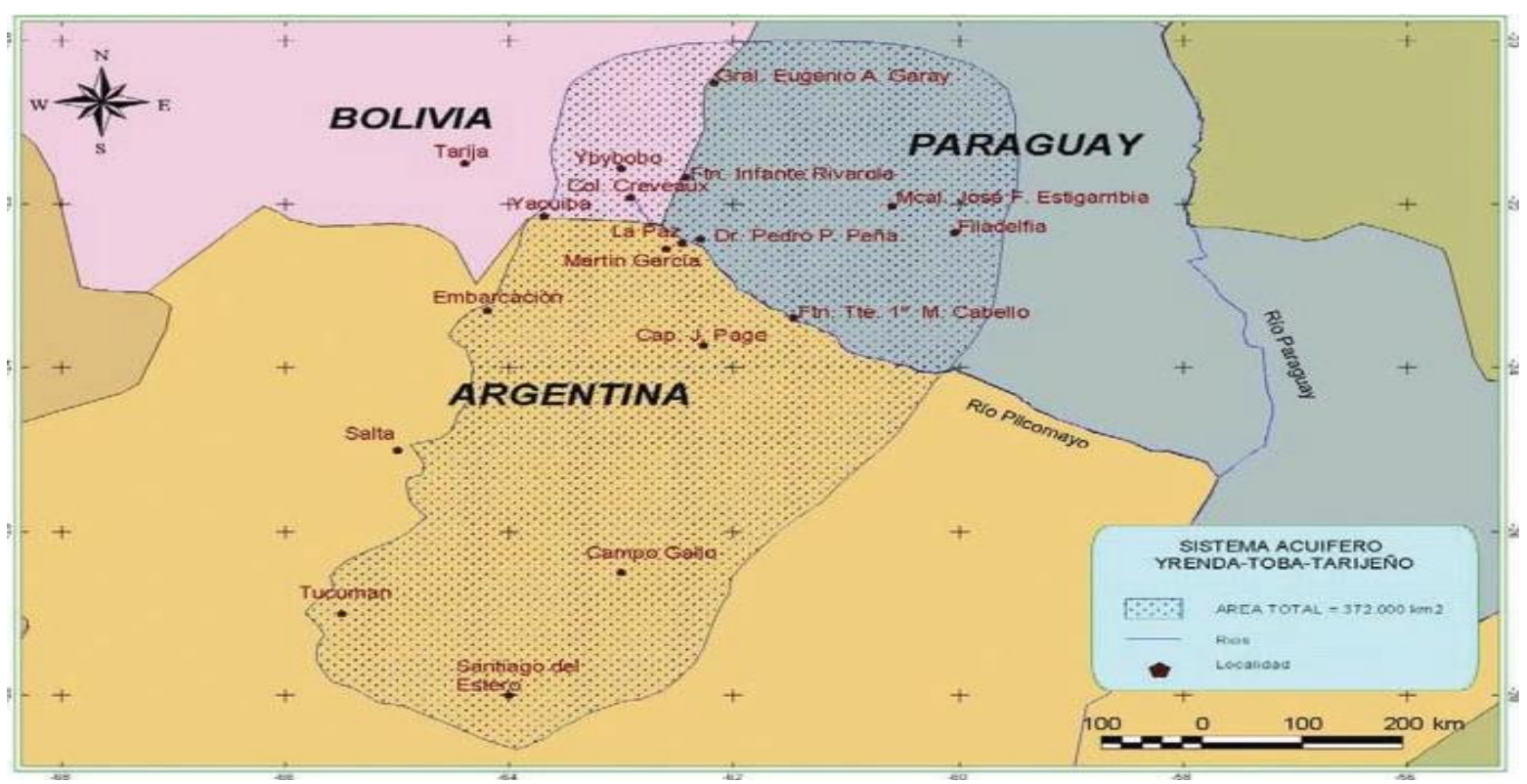

Fonte: UNESCO/ISARM AMERICAS (2010).

Ortega e Portillo (2015) denunciaram a iniciativa governamental do governo paraguaio para beneficiar a extração de petróleo por faturamento hidráulico (fracking) nas áreas abrangidas por esse sistema aquífero. Essas empresas usam equipamentos de alta pressão com água e produtos químicos para fraturar a rochas, de modo que as águas subterrâneas correm riscos de contaminação por hidrocarbonetos e resíduos tóxicos.

Segundo o CIC (2016), a área de ocorrência desse complexo hídrico é de cerca de $400.000 \mathrm{~km}^{2}$, tendo como principais cursos de águas superficiais os rios Pilcomayo, Bermejo, San Telmo, Salado, Grande de Tarija e Guadalquivir. Constitui um Sistema Aquífero livre, multicamadas, composto por sedimentos terciários e quaternários, apresentando ampla movimentação tectônica e originando zonas úmidas influentes na regulação natural do regime das chuvas.

Os poços nesse sistema apresentam vazões bastante variadas, desde 1 a $20 \mathrm{~m}^{3} / \mathrm{h}$ e, do ponto de vista químico, caracterizam-se pela alternância de camadas portadoras de águas doces com outras que exibem altos graus de salinização (CIC, 2016).

\section{Sistema Aquífero Pantanal}

Esse Sistema está localizado na bacia hidrográfica do Rio Paraguai, com uma área estimada de $141.500 \mathrm{~km}^{2}$, compartilhada entre Brasil $\left(102.000 \mathrm{~km}^{2}\right)$, Bolívia $\left(21.500 \mathrm{~km}^{2}\right)$ e Paraguai $\left(18.000 \mathrm{~km}^{2}\right)$. É um aquífero livre ou freático, poroso e permeável, e vulnerável à poluição, devido à forte pressão das atividades produtivas, principalmente as ligadas aos grandes territórios agrícolas com intenso uso de agrotóxicos e territórios de criação de gado.

O Sistema Aquífero Pantanal é de grande significado no equilíbrio do ecossistema Pantanal, a maior área úmida do mundo, declarada Patrimônio da Humanidade e integrante da Convenção Mundial de Ramsar ${ }^{4}$. Apesar da legislação, inclusive mencionada na Constituição Brasileira de 1988 (BRASIL,1988), na realidade, o ecossistema do Pantanal está ameaçado de várias formas, algumas com reflexos diretos nas águas subterrâneas, como o elevado assoreamento dos rios - originado pela

\footnotetext{
${ }^{4}$ A Convenção é um tratado intergovernamental em vigor desde 1975, criado no intuito de proteger os habitats
} aquáticos importantes para a conservação de aves migratórias (BRASIL, 2021).

$\begin{array}{lllll}\text { Caminhos de Geografia } & \text { Uberlândia-MG } & \text { v. 23, n. } 85 & \text { fev./2022 } & \text { p. 191-203 Página } 196\end{array}$


grande erosão advinda do desmatamento e queimadas, em áreas de planalto - que diminui a infiltração e recarga do aquífero.

Essa perspectiva analítica remete a Britto, Silva e Anache (2016), revelando a dinâmica do desmatamento:

o processo de desmatamento está ligado a uma complexa rede de relações de poder político, econômico e social, historicamente materializada no espaço por meio de distintas formas de territorialização. Sua magnitude e frequência são resultantes de múltiplos arranjos entre estado, capital e distintos atores sociais (BRITTO; SILVA; ANACHE, 2016, p. 60).

Esse processo demonstra que as commodities, do sempre atuante mercado financeiro, operam através do uso da terra e a utilização das mais agressivas técnicas substituem os aspectos naturais do bioma, criando as mais diversas externalidades para os grupos sociais e o meio ambiente nas suas múltiplas escalas. Esses grandes empreendedores agrícolas se inserem em espaços que tenham disponibilidade de água, no território desse sistema aquífero existe um adequado índice pluviométrico, com médias entre $1.000-1.500 \mathrm{~mm}$, em clima mesotérmico e cotas topográficas variando entre 100 metros e 200 metros, representando uma extensão ao norte do Chaco Paraguaio. As vazões máximas dos poços atingem os $10 \mathrm{~m} 3 / \mathrm{h}$, embora as médias sejam sempre em suas áreas de descarga. Subjacente a essas unidades ocorre expressivo número de aquíferos confinados.

Os dados registrados pelo CIC (2016) classificam que no geral as águas subterrâneas pertencente ao Sistema Aquífero Pantanal são de boa qualidade, embora localmente ocorram expressivos índices de carbonatos, ferro, matéria orgânica e águas salobras. O sistema aquífero é do "tipo multicamadas, constituído de sedimentos Terciários e Quaternários não consolidados a pouco consolidados, predominantemente arenosos. O fluxo é geralmente em direção ao rio Paraguai com rumo Sudoeste do lado brasileiro e rumo Sudeste na Bolívia e no Paraguai” (CIC, 2016, p.20).

\section{Sistema Aquífero Água Doce}

No Paraguai, se constitui como um aquífero regional de alto potencial, em grande parte inexplorado, com extensão em torno dos $30.000 \mathrm{~km}^{2}$. Dados técnicos apresentados pelo CIC (2016) expressam que os poços na área indicam uma vazão de até $36 \mathrm{~m} 3 / \mathrm{h}$, com águas de muito boa qualidade.

A área de influência do Sistema Água Doce se subdivide nos climas semiárido a tropical úmido a leste e seco a oeste, com invernos secos e uma temperatura ambiente que varia entre 18 e $26{ }^{\circ} \mathrm{C}$. A precipitação anual varia entre $1.400-1.500 \mathrm{~mm}$.

A geografia física regional é caracterizada como Chaco Liso, com algumas ocorrências de colinas e montanhas isoladas. Quanto à população, é considerada dispersa e reduzida, dedicada ao cultivo agrícola e criação de gado. É um dos poucos aquíferos de água doce em escala local, podendo se constituir na solução para o desenvolvimento sustentável na Região. É de grande importância para o uso na irrigação e consumo humano (CIC, 2016).

\section{Sistema Aquífero Bauru/Caiuá - Acaray}

O Aquífero Acaray é do tipo livre com espessura média de 200 metros, composto por arenitos finos e grossos, com alta permeabilidade. De idade Cretácea, está situado em cima dos Sistemas Aquíferos Serra Geral e Guarani, o que facilita seu aproveitamento econômico, mas aumenta sua venerabilidade. Aplicam-se as denominações de Formação Caiuá e Formação Bauru no Brasil e Formação Acaray no Paraguai. A direção do fluxo predominante é em direção ao Rio Paraná (CIC, 2016).

O aquífero na Unidade Caiuá tem um alto potencial de exploração com vazões entre 40 e $60 \mathrm{~m} 3 / \mathrm{h}$. Na Unidade Bauru as vazões são moderadas, variando de 10 a $20 \mathrm{~m}^{3} / \mathrm{h}$. A água é de boa qualidade, com ocorrência de águas minerais, sendo muito explotado nos Estados de São Paulo e Paraná, enquanto que no estado de Mato Grosso do Sul e Paraguai sua utilização é menor. As águas são usadas principalmente para o consumo humano e na pecuária, mas as áreas são também intensamente utilizadas para extensas monoculturas, advindo daí problemas de contaminação, através de fertilizantes e agrotóxicos (CIC, 2016). O aquífero é de importância hidrogeológica regional, de boa qualidade da água e poços de alta produtividade para irrigação, água mineral e uso agropastoril (no Paraguai).

$\begin{array}{lllll}\text { Caminhos de Geografia } & \text { Uberlândia-MG } & \text { v. 23, n. } 85 & \text { fev./2022 } & \text { p. 191-203 Página } 197\end{array}$




\section{Sistema Aquífero Aquidauana - Aquidabán}

Nos dois países, Brasil e Paraguai, suas águas são utilizadas para o abastecimento humano e animal, facilitando o desenvolvimento econômico do território agrícola e pecuário em que está inserido, e parte de sua área de ocorrência situa-se na área de proteção do ecossistema Pantanal.

O Sistema Aquífero Transfronteiriço Aquidauana - Aquidabán está localizado na bacia do rio Paraná, com uma área de aproximadamente $27.000 \mathrm{~km}^{2}$, dos quais $14.600 \mathrm{~km}^{2}$ estão no Brasil e $12.300 \mathrm{~km}^{2}$ no Paraguai, estendendo-se na direção NE - SW, sendo utilizado no abastecimento humano e animal tanto no Brasil quanto no Paraguai (DINIZ et al., 2014)

O clima regional é quente no verão, com temperatura média de $32{ }^{\circ} \mathrm{C}$ e frio e seco no inverno, com média em torno de $21^{\circ} \mathrm{C}$. A precipitação é de cerca de $1.000-1.500 \mathrm{~mm}$, concentrados no verão, e o relevo é plano a suavemente ondulado, com altitudes entre $400 \mathrm{~m}$ e $800 \mathrm{~m}$. O aquífero é do tipo semiconfinado, constituído por sedimentos glácio-marinhos com intensas variações de fácies, apresentando vazões também bastante dispersas, com valores médios oscilando entre 10-20 $\mathrm{m}^{3} / \mathrm{h} /$ poço. Do ponto de vista químico, também apresenta águas com características bastante variáveis (CIC, 2016).

\section{Sistema Aquífero Serra Geral (SASG)}

O Sistema Aquífero Serra Geral é também transfronteiriço, compartilhado pelo Brasil $\left(411.855 \mathrm{~km}^{2}\right)$, Argentina $\left(540.000 \mathrm{~km}^{2}\right)$, Paraguai $\left(29.500 \mathrm{~km}^{2}\right)$ e Uruguai $\left(40.000 \mathrm{~km}^{2}\right)$, somando um total de $1.021 .336 \mathrm{~km}^{2}$ (UNESCO/ISARM AMERICAS, 2010).

A cobertura de basaltos constitui-se num aquífero fraturado, da Formação Serra Geral (com até mais de $1.500 \mathrm{~m}$ de espessura), que cobre o Aquífero Guarani, de forma a reduzir sua área de exposição a apenas $10 \%$ da sua área total de distribuição geográfica, e por essa razão ambos são considerados, especialmente para fins de gestão, como um Sistema Aquífero Integrado Guarani/Serra Geral, o SAIG/SG. (SCHEIBE; HIRATA, 2008).

O SASG é amplamente explotado nos quatro países do Mercosul, para o abastecimento humano, uso industrial e irrigação. Constitui um sistema aquífero do tipo livre a semiconfinado, fraturado e constituído por derrames de lavas basálticas das formações localmente chamadas de Alto Paraná (PY), Serra Geral (BR) e Arapey (AR e UY).

Devido às características das rochas basálticas fraturadas, as taxas de vazões são variáveis, dependendo da região, do tipo e da distribuição das fraturas. Informa a UNESCO/ISARM AMERICAS (2010) que na Argentina essa variabilidade pode ocorrer entre 10 a $100 \mathrm{~m} 3 / \mathrm{h}$; no Uruguai, esses fluxos variam entre 5 a $20 \mathrm{~m} 3 / \mathrm{h}$, sendo que em alguns locais específicos no país chegam a oscilar entre 0,50 a $1,4 \mathrm{~m}^{3} / \mathrm{h}$. No Brasil, apresenta vazões muito variáveis, valores entre 10 e $100 \mathrm{~m} / \mathrm{h}$, e é intensamente usado no triângulo mineiro, pequena parte de São Paulo, Mato Grosso do Sul e nos estados do Sul (RS, SC, PR). Nestes estados, o aquífero Serra Geral desempenha função importante, pois por seu carácter não confinado, suas águas são exploradas através de poços relativamente rasos e geralmente têm ligação direta com as águas da superfície. Isto as torna muito mais acessíveis, mas também muito mais vulneráveis aos processos de contaminação, tanto pelas próprias fraturas das rochas como pelas características construtivas dos poços (SCHEIBE e HIRATA, 2008).

No Oeste do estado de Santa Catarina, um considerável levantamento com base em 1.302 poços tubulares estima que o uso humano era de $83,72 \%$, industrial $8,52 \%$, agrícola e animal $5 \%$ e de recreação através do turismo termal nas estâncias minerais de 2,76\% (FREITAS; CAYE; MACHADO, 2002). Contudo, essa região é agroexportadora de frangos e suínos e utiliza águas subterrâneas para essa finalidade, porém, não se tem dados oficiais de quantidades específicas de águas utilizadas por essas empresas.

Rosa Filho (2011) descreve a função estratégica econômica dos aquíferos constituídos por basaltos, desde a reconhecida fertilidade dos solos, base de intensa exploração agropecuária, característica da região, até os condicionamentos favoráveis (topográficos e geotécnicos) à implantação de hidrelétricas.

No Paraguai, os principais usos são: irrigação, 5\%; doméstica, $80 \%$; e industrial, $15 \%$; no Uruguai, as águas desse sistema aquífero são utilizadas para: irrigação, doméstica e indústria e turismo termal;

$\begin{array}{llllll}\text { Caminhos de Geografia } & \text { Uberlândia-MG } & \text { v. 23, n. } 85 & \text { fev./2022 } & \text { p. 191-203 } & \text { Página } 198\end{array}$


na Argentina, se utiliza para abastecimento humano e industrial (UNESCO/ISARM AMERICAS, 2010).

Segundo Nanni (2008), suas águas são bicarbonatadas cálcicas e sódicas, apresentando eventualmente mistura com águas do SAG. No Rio Grande do Sul, o clima da região de ocorrência do SASG é úmido a semiúmido, com precipitação média anual entre $1.200 \mathrm{~mm}$ e $1.500 \mathrm{~mm}$. A explotação deste aquífero para abastecimento humano e industrial é alta, e tem grande potencial turístico. Explica Nanni (2008, p. 80) "aproximadamente $80 \%$ da demanda de água das cidades localizadas na área coberta pelo vulcanismo Mesozoico da Bacia do Paraná no Rio Grande do Sul é suprida pela exploração do SASG".

Além de fisicamente ser importante para a conservação do ecossistema dependente e também para garantir o fluxo de base dos rios da região, é inferida uma conexão hidráulica entre o sistema Serra Geral e o Aquífero Guarani, conforme tese defendida por Descovi Filho (2015), sendo parte da Meta 01 do já referido projeto Rede Guarani/Serra Geral (RGSG). Descovi Filho (2015), obteve informações de 132 poços que atingem o contato do Serra Geral com o SAG em Santa Catarina, disponibilizando dados referentes a espessuras do pacote vulcânico e a definição de (pelo menos) 14 blocos tectônicos hidrogeológicos nesse estado, com as espessuras médias do Grupo Serra Geral, variando desde zero (0) metro até 1.132 metros.

\section{Sistema Aquífero Permocarbonífero}

Conforme o CIC (2016) esse sistema aquífero é relevante fonte de abastecimento em escala local no uso doméstico das pequenas populações dispersas na zona fronteiriça Uruguai/Brasil; seus afloramentos ocorrem na porção sul do Brasil e nordeste do Uruguai.

O Sistema Aquífero Transfronteiriço Permo - Carbonífero está localizado na bacia hidrográfica do Rio Uruguai, com uma área de $41.000 \mathrm{~km}^{2}$, sendo $20.000 \mathrm{~km}^{2}$ no Uruguai e $21.000 \mathrm{~km}^{2}$ no Brasil. Aflora na porção sul do Brasil e nordeste do Uruguai, entre as latitudes $30^{\circ}$ a $34^{\circ} \mathrm{S}$ e longitudes $52^{\circ}$ e $56^{\circ} \mathrm{W}$ , continuando em superfície na parte oriental dessas áreas (DINIZ et al, 2014)

A região é conhecida como Depressão Central Gaúcha, constituindo uma área sem grandes variações altimétricas; os pontos mais altos estão localizados a cerca de $200 \mathrm{~m}$, com relevo conhecido como de coxilhas. O clima é temperado úmido, com chuvas ao longo de todo o ano, precipitações médias de $1.500 \mathrm{~mm} /$ ano e temperatura variando entre $22^{\circ} \mathrm{C}$ e $3^{\circ} \mathrm{C}$. O aquífero é poroso, não consolidado a consolidado e de baixa produtividade. Está incluída a unidade Tres Islas no Uruguai, constituindo-se de arenitos finos a médios com níveis de areia grossa e cascalho, exibindo forte cimentação argilosa no Brasil. Os dados de poços disponíveis e as características litológicas das unidades demonstram baixas potencialidades hidrogeológicas, segundo estudos revelados pelo $\mathrm{CIC}$ (2016).

\section{Função das águas subterrâneas e seus benefícios estratégicos}

No ano de 2010, foi publicado pelo Escritório Regional de Ciência para América Latina e Caribe das Nações Unidas para a Educação, a Ciência e a Cultura (UNESCO), Programa Hidrológico Internacional (PHI) e Departamento de Desenvolvimento Sustentável (DDS) da OEA, o ISARM Américas Series, o Documento $n^{\circ} 3$, para cuja elaboração foi utilizado um questionário organizado para ser respondido pelos países membros, responsáveis pela gestão das águas subterrâneas, para obtenção de dados/informações disponíveis sobre os aquíferos transfronteiriços das Américas do Norte, Central e Sul.

Conforme o documento (UNESCO/ISARM AMERICAS, 2010), apesar da falta de dados específicos sobre a importância dos aquíferos para a economia, fica evidente que existem múltiplos usos e funções das águas dos aquíferos nas Américas, para criação de animais, pesca e agricultura (cultivo de arroz vale cerca de US \$60 milhões por ano) e para atividades turísticas, (estimado em US \$30 milhões no Uruguai em 2007), mas o maior uso é especialmente para manter as necessidades fisiológicas das pessoas, tanto no espaço rural como no urbano - além do uso da água pelas comunidades indígenas. Na cidade de Ribeirão Preto, Brasil, por exemplo, seus 567,9 mil habitantes dependem do aquífero, como outras de grande parte da região (Paraguai, Uruguai, Argentina e Brasil) (UNESCO/ISARM AMERICAS, 2010, p. 22-23). 
Alguns dados sobre os usos das águas do SAG, baseados na vazão de 2.054 poços, adotando-se um regime de operação média de 18 horas por dia, foram apresentados pela OEA no ano de 2009:

o volume de água extraída do SAG foi estimado em 2.847.013,5 m³/dia, ou seja, aproximadamente $1,04 \times 109 \mathrm{~m}^{3} /$ ano. O principal uso atual da água do SAG, seja em número de poços ou em vazão extraída, é o abastecimento público. Na Argentina, os poços registrados são explorados unicamente para fins recreativos. No Uruguai e no Paraguai, mais de $90 \%$ da água extraída são destinadas ao abastecimento dos centros urbanos. (OEA, 2009, p. 141).

$\mathrm{Na}$ Argentina, segundo dados registrados pelo CIC (2016), as zonas com maior utilização da água subterrânea para abastecimento humano estão situadas nas proximidades de Buenos Aires, contudo, ela é usada para as atividades agropecuárias em todo o país. Na Bolívia, os principais usos são para o abastecimento da população, agricultura e indústria; já no Brasil, a água subterrânea tem importância fundamental para o abastecimento humano (p. ex. Ribeirão Preto), uso industrial em toda a região sudeste (grande exploração na Região Metropolitana de São Paulo) e sul: por exemplo, no oeste do estado de Santa Catarina, região com intensa exportação agroindustrial de carnes, tendo sua base de desenvolvimento na disponibilidade hídrica, hoje parcialmente comprometida pela intensa poluição das águas superficiais (UNESCO/ISARM AMERICAS, 2010).

No Paraguai, a água subterrânea é amplamente utilizada para abastecimento humano, no entorno da capital do País, e industrial, e nas demais regiões dispersas, além de também para criações de animais.

O CIC produziu pesquisa no ano de 2016 sobre águas subterrâneas, identificando dados técnicos sobre a densidade dos poços profundos nos países platinos, que variam de 1,5 a 70 poços a cada 10 $\mathrm{km}^{2}$. Essa variação ocorre pelo fato de que algumas áreas somente utilizam águas subterrâneas, como é o caso de Ribeirão Preto, em São Paulo. Conforme dados da ANA (2010), 52\% dos 5.570 municípios brasileiros são abastecidos total $(36 \%)$ ou parcialmente $(16 \%)$ por águas subterrâneas. A explotação desse recurso hídrico é inversamente proporcional ao tamanho das cidades. As águas subterrâneas são a opção exclusiva para $48 \%$ dos municípios com população menor que 10 mil habitantes e para $30 \%$ daqueles com 10 a 50 mil habitantes. Quando questionado a respeito dessa dependência, foram obtidas as seguintes respostas:

no Paraguai, a pecuária e a agricultura, que se intensificaram nos últimos 20 anos, foram afetadas. $90 \%$ da água é utilizada para a agricultura, $5 \%$ para a indústria e $5 \%$ para o comércio transfronteiriço. O Uruguai usa aquíferos para apoiar o ecoturismo em estâncias costeiras e para o turismo termal. A economia da Argentina é altamente dependente da água, especialmente para seu desenvolvimento econômico regional no setor agrícola (UNESCO/ISARM AMERICAS, 2010, p. 22).

Esses dados demonstram que esses territórios dependem do acesso à água subterrânea para suas economias: agricultura, indústria, recursos naturais, biodiversidade. Outra questão que se descortina, refere-se à importância de considerar nas atividades de planejamento, para melhor gestão, a integração das águas superficiais e subterrâneas associando questões de origem antrópica.

Pires do Rio e Drummond (2013, p. 217) reconhecem que na escala dos países platinos existem deficiências na gestão das águas, necessitando conhecimentos "[...] sobre quantidade, qualidade e necessidades segundo as diferentes zonas e regiões. Para um mesmo uso as necessidades podem variar segundo as técnicas empregadas, as condições de acesso à água, os sistemas de gestão desenvolvidos", etc.

Nessa linha de pensamento, Hirata et al. (2019) recomendam ações para a proteção das águas subterrâneas tendo por base os seguintes pilares:

I)comunicação com vistas à conscientização da sociedade e do governo sobre o real papel social e ambiental e valor econômico das águas subterrâneas; II) fortalecimento dos órgãos de controle e gestão dos recursos hídricos, sobretudo aqueles associados à fiscalização e disciplinamento do uso das águas; III) ampliação da cobertura de coleta e tratamento de esgotos; e IV) criação de programas permanentes de proteção das águas subterrâneas, baseados em pesquisa e estudos técnicos (HIRATA et al. 2019, p.29).

Os autores ainda fazem outras recomendações tais como: "inserção de práticas de gestão integrada, ampliar estudos hidrogeológicos, planos de monitoramento e fiscalização conjuntos, programas de identificação de áreas críticas do recurso hídrico subterrâneo" (HIRATA et al., 2019). Ou seja, as águas subterrâneas são importantes, necessárias e precisam ser visíveis para as pessoas e para os governos desenvolverem políticas públicas e gestão integrada 


\section{CONSIDERAÇÕES FINAIS}

A bacia do Prata é um território vigoroso, diversificado e competitivo, responsável por $70 \%$ do PIB desses países e que acomoda $50 \%$ da população, além dos mais extensos rios do continente, abrigando em suas entranhas, o imenso espaço das águas subterrâneas, um dos maiores e mais importantes sistemas aquíferos do mundo, o Sistema Aquífero Guarani (SAG), com toda sua complexidade (CIC, 2016), e que, em conjunto com o Sistema Aquífero Serra Geral (SASG), forma o Sistema Aquífero Integrado Guarani/Serra Geral (SAIG/SG) (SCHEIBE e HIRATA, 2008).

Fica evidente neste estudo que, além da abundância das águas superficiais da Bacia do Prata, o potencial dos diferentes sistemas aquíferos da América do Sul constitui importante fator de integração e de consolidação histórica dos países da Bacia, inclusive para a formação de blocos econômicos, especialmente, o Mercosul.

Os resultados deste levantamento teórico e documental assinalam a importante função da água nos diferentes segmentos da economia do território platino, em destaque a ação produtiva de grãos (soja, milho, arroz, algodão, cana de açúcar), irrigação, abastecimento animal, indústria e o turismo, evidenciando que cada vez mais a água subterrânea desempenha um papel relevante e geoestratégico na dinâmica dos processos produtivos, podendo se constituir em parte da solução para o desenvolvimento sustentável desses países.

Ainda, foi possível observar que as demandas para o consumo da população estão crescendo, principalmente nos centros urbanos, comprovando que as águas subterrâneas apresentam papel importante como fonte de abastecimento das populações, mas que seu uso precisa ser otimizado para as futuras gerações possam também usufruir deste recurso. Deve, portanto, ser analisado pelos gestores dos países platinos o custo/benefício de seu aproveitamento imediato, para exercerem governança hídrica e políticas adequadas para a conservação e proteção desses aquíferos transfronteiriços.

Outro aspecto que necessita de atenção e análise, trata da importância de todos os países construírem políticas, diretrizes e legislações próprias para a proteção dos aquíferos compartilhados em seus territórios. Contudo, essas nações devem considerar a bacia em sua totalidade, além das fronteiras nacionais, tanto na aplicação de dispositivos legais, quanto na fiscalização dessas linhas imaginárias que demarcam o seu território hídrico.

Não restam incertezas de que a gestão de forma cooperativa produz resultados mais promissores do que aqueles forjados individualmente por cada país. O benefício coletivo exige cada vez mais ações que contrariam os interesses exclusivos de cada nação.

Nesse horizonte, é indubitavelmente necessários conhecimentos por meio de novas pesquisas com dados sobre as águas subterrâneas para planejar e gestar ações visando identificar a potencialidade dos recursos hídricos para sustentar a dinâmica econômica, especialmente a do agronegócio com seus nexos estruturantes do território: água, solo, energia, hidrovias, seus impactos locais, e a competição com os outros usos, particularmente, o abastecimento público.

Ainda, há um caminho a ser percorrido, por futuras pesquisas, para conhecimento das questões de ordem de natureza física, para compreensão da dinâmica das interações binárias: águas superficiais e subterrâneas. Além do aprofundamento dos conhecimentos hidrológicos, não podem ser sonegados os aspectos econômicos, sociais, políticos e ecológicos, em consonância com a realidade de cada país

\section{REFERÊNCIAS}

ANA - Agência Nacional de Águas (Brasil). Atlas Brasil: abastecimento urbano de água: panorama nacional/Agência Nacional de Águas; Engecorps/Cobrape - Brasília: ANA : Engecorps/Cobrape, 2010. Disponivél em:

http://atlas.ana.gov.br/Atlas/downloads/atlas/Resumo\%20Executivo/Atlas\%20Brasil\%20\%20Volume\%201\%20-\%20Panorama\%20Nacional.pdf .Acesso em: 31 jan. 2021.

BRASIL. Constituição da República Federativa do Brasil. Brasília, DF: Senado Federal. 1988. Disponível: http://www.planalto.gov.br/ccivil 03/Constituicao/Constituicao.htm. Acesso em: 31 jan. $\underline{2021 .}$

$\begin{array}{lllll}\text { Caminhos de Geografia } & \text { Uberlândia-MG } & \text { v. 23, n. } 85 & \text { fev./2022 } & \text { p. 191-203 Página } 201\end{array}$


MINISTÉRIO DO MEIO AMBIENTE. Áreas Úmidas: Convenção de Ramsar 1975.

Disponível em: https://antigo.mma.gov.br/biodiversidade/biodiversidade-aquatica/zonas-umidasconvencao-de-ramsar. Acesso em: 03 fev. 2021

BRITTO, Fabio Giusti Azevedo de; SILVA, Simone dos Santos Sodré da.; ANACHE, Bernardo Mansur. Técnica, território e impactos ambientais no "celeiro" das commodities agrícolas. In: BERNARDES, Júlia Adão; BUHLER, Éve Anne; COSTA, Marcos Vinícius Velozo da (Org.). As novas fronteiras do Agronegócio: transformações territoriais em Mato Grosso. Rio de Janeiro: Lamparina,.2016, $168 \mathrm{p}$.

CIC - Comitê Intergovernamental Coordenador dos Países da Bacia do Prata. Análisis diagnóstico transfronterizo de la cuenca del plata - ADT. Buenos Aires: CIC .(2016). Disponível em: https://cicplata.org/es/documentos-principales/. Acesso em: 31 jan. 2021.

DESCOVI FILHO, Leônidas Luiz Volcato. Geomorfoestruturas e compartimentação tectônica do sistema aquífero integrado Guarani/Serra Geral no estado de Santa Catarina, Brasil. 224 f. Tese (Doutorado em Geografia) - Universidade Federal de Santa Catarina, Florianópolis, 2015. Disponível em: <http://www.bu.ufsc.br/ teses/PGCN0595-T.pdf>. Acesso em: 31 jan. 2021.

DINIZ, João Alberto Oliveira, MONTEIRO; Adson Brito, SILVA; Robson de Carlo da; PAULA, Thiago Luiz Feijó de. Mapa hidrogeológico do Brasil ao milionésimo: Nota técnica - Recife: CPRM Serviço Geológico do Brasil, 2014.

FREITAS, Marcos Alexandre; CAYE, Bráulio Robério; MACHADO, José Luiz Flores (Org.). PROESC: Diagnóstico dos recursos hídricos subterrâneos do oeste do Estado de Santa Catarina Projeto Oeste de Santa Catarina. Porto Alegre: CPRM/SDM-SC/SDA-SC/EPAGRI.2002. Disponível em: http://www.aguas.sc.gov.br/jsmallfib top/DRHI/Aguas\%20Subterraneas/01-relatorio.pdf .Acesso em: 31 jan. 2021.

HIRATA, Ricardo; SUHOGUSOFF, Alexandra Vieira; MARCELLINI, Silvana Susko; VILLAR, Pilar Carolina; MARCELLINI, Laura. A revolução silenciosa das águas subterrâneas no Brasil: uma análise da importância do recurso e os riscos pela falta de saneamento. Instituto Trata Brasil. SP. 2019.

NANNI, Arthur Schmith. O flúor em águas do Sistema Aquífero Serra Geral no Rio Grande do Sul: origem e condicionamento geológico. 2008. Tese (Doutorado em Geociências) - Instituto de Geociências, Universidade Federal do Rio Grande do Sul, Porto Alegre, 2008.

OEA - Organização dos Estados Americanos. Aquífero Guarani: Programa Estratégico de Ação Acuífero Guaraní: Programa Estratégico de Acción - Brasil; Argentina; Paraguai; Uruguai: Organização dos Estados Americanos, jan. 424 p., (2009). Disponível em: <http://www2.ana.gov.br/Paginas/projetos/GEFAquiferoGuarani.aspx>. Acesso em: 31 jan. 2021.

ORTEGA, Guillermo. PORTILLO, Ana. El agua: ¿bien común o mercancía?. Asunción: Investigaciones Sociales BASE .(2015). Disponível em: http://biblioteca.clacso.edu.ar/Paraguay/baseis/20170331044501/pdf 1236.pdf. Acesso em: 19 dez. 2020

PIRES DO RIO, Gisela; DRUMMOND, Helena Ribeiro. Água e espaços transfronteiriços na América do Sul: questões a partir do Território. Sustentabilidade em Debate, Brasília, v. 4, n. 1, p. 209-230, jan./jun. (2013). Disponível em: <http://periodicos.unb.br/index.php/sust/ article/view/9208>. Acesso em: 28 jan. 2021.

PROJETO DE PROTEÇÃO AMBIENTAL E DESENVOLVIMENTO SUSTENTÁVEL DO SISTEMA AQUÍFERO GUARANI - PSAG. Disponível em:

https://sites.google.com/site/aabrasilma/Home/planos-de-acao/ds/dsrh/recursoshidricos/projetosistemaaqueiferoguarani-psag. Acesso em: 2 nov. 2020

RGSG - REDE GUARANI/SERRA GERAL. Disponível em: http://rgsgsc.wordpress.com/metas/. Acesso: 04 mar. 2021.

RIBEIRO, Wagner Costa. Geografia política da água na América Latina. In: XI ENCONTRO DE GEÓGRAFOS DA AMÉRICA LATINA - Geopolítica, globalização e mudanças ambientais: Desafios no desenvolvimento latino-americano. Anais... Bogotá: Universidad Nacional de Colombia, 26 a 30 março 2007. Disponível em:

<http://observatoriogeograficoamericalatina.org.mx/egal11/Geografiasocioeconomica/Geografiapolitic a/06.pdf>. Acesso em: 28 jan. 2021.

$\begin{array}{lllll}\text { Caminhos de Geografia } & \text { Uberlândia-MG } & \text { v. 23, n. } 85 & \text { fev./2022 } & \text { p. 191-203 Página } 202\end{array}$


ROSA FILHO, Ernani Francisco da. Aquífero Guarani: uma reserva de água salobra? In: CARUSO, Raimundo C. (Org.). Desafios de Foz de Iguaçu: educação, saúde e segurança. Florianópolis: Ofício, 2011.

SCHEIBE, Luiz Fernando; HIRATA, Ricardo César Aoki. O contexto tectônico dos sistemas Aqüíferos Guarani e Serra Geral em Santa Catarina: uma revisão In: CONGRESSO BRASILEIRO DE ÁGUAS SUBTERRÂNEAS, 15., 2008, Natal. Anais... Natal: Associação Brasileira de Águas Subterrâneas. v. 1. Disponível em: https://aguassubterraneas.abas.org/asubterraneas/article/view/23794/15859. Acesso em: 20 dez. 2020.

SOLDERA, Bruna Camargo. Monitoramento dos níveis freáticos do Aquífero Bauru (Formação Adamantina) no Município de Assis-SP. Rio Claro: Associação Brasileira de Águas Subterrâneas, 1a Edição, 2016. Disponível em: <https://multimedia.getresponse.com/getresponseSt4bF/documents/556908602.pdf?_ga=2.201092462.1964885295. 1494880680565886650.1485542732>. Acesso em: 19 dez. 2020.

SOUZA, Matilde de; SILVA, Carla Pereira, BARBOSA; Luciana Mendes. Governança e difusão de Normas para a Gestão de Aquíferos Compartilhados: o papel do ISARM. Contexto Internacional, v. 36, n. 1, 2014, p. 261-289 Disponível em: <http://contextointernacional.iri. pucrio.br/media/v36n1a09.pdf>. Acesso em: 28 jan. 2021.

UNESCO - Organização das Nações Unidas para a Educação, a Ciência e a Cultura. ISARM Internationally Shared Aquifer Resources Management. Acuíferos transfronterizos de las Américas: aspectos socioeconómicos, ambientales y climáticos de los sistemas acuíferos transfronterizos de las Américas. Vol.3 Washington: UNESCO, 2010. Disponível em: http://isarmamericas.org/wp-content/uploads/2019/06/Libro-3.pdf . Acesso em: 01 fev. 2021.

Recebido em: 20/10/2020

Aceito para publicação em: 22/03/2021 